\title{
Specificities of a chemically modified laccase from Trametes hirsuta on soluble and cellulose-bound substrates
}

\author{
M. Schroeder · S. Heumann · C. J. S. M. Silva • \\ A. Cavaco-Paulo - G. M. Guebitz
}

Received: 15 November 2005/ Accepted: 9 January 2006/Published online: 30 May 2006

(C) Springer Science+Business Media B.V. 2006

\begin{abstract}
Laccases could prevent fabrics and garments from re-deposition of dyes during washing and finishing processes by degrading the solubilized dye. However, laccase action must be restricted to solubilized dye molecules thereby avoiding decolorization of fabrics. Chemical modification of enzymes can provide a powerful tool to change the adsorption behaviour of enzymes on water insoluble polymers. Polyethylene glycol (PEG) was covalently attached onto a laccase from Trametes hirsuta. Different molecular weights of the synthetic polymer were tested in terms of adsorption behaviour and retained laccase activity. Covalent attachment of PEG onto the laccase resulted in enhanced enzyme stability while with increasing molecular weight of attached PEG the substrate affinity for the laccase conjugate decreased. The activity of the modified laccases on fibre bound dye was drastically reduced decreasing the adsorption of the enzyme on various fabrics. Compared to the $5 \mathrm{kDa}$ PEG laccase conjugate (K/S value 47.60)
\end{abstract}

\footnotetext{
M. Schroeder · S. Heumann · G. M. Guebitz $(\bowtie)$ Department of Environmental Biotechnology, Graz University of Technology, Petersgasse 12, A-8010 Graz, Austria

e-mail: guebitz@tugraz.at

C. J. S. M. Silva · A. Cavaco-Paulo

Textile Engineering Department, University of Minho, 4800-058 Guimarães, Portugal
}

the K/S value decreased much more (47.96-46.35) after the treatment of dyed cotton fabrics with native laccase.

Keywords Laccase Polyethylene glycol · Dye-degrading $\cdot$ Enzyme modification ·

Trametes hirsuta

\section{Introduction}

Indigo and Remazol Briliant Blue $\mathrm{R}$ are widely applied industrial dyes. Previous studies have shown the degradation of different commercial dyes using crude and purified laccases from Trametes hirsuta (Campos et al. 2001; Rodriguez Couto et al. 2005). Besides the reduction of environmental pollution (Nyanhongo et al. 2002; Sorares et al. 2001), enzymatic decolourisation of dyeing effluents has been shown to enable re-use of the treated water in dyeing (Abadulla et al. 2000). Furthermore, laccase has been introduced for indigo oxidation on denim garments (Galante and Formantici 2003), so called 'biobleaching' and removal of extensive dye after dyeing.

Re-deposition of Indigo dye during enzymatic stone-washing of denim garments with cellulases seems to be a major problem (Cavaco-Paulo 1998; Andreaus and Campos 2001). Similar effects occur during the washing process in the household laundry of coloured garments. Laccases 
could decolourize solubilized dyes preventing their redeposition on fabrics and garments. However, beside the dye degradation in aqueous solutions native laccases are also capable of degrading dyes like Indigo on fabrics (Campos et al. 2001). Thus, a protection of the dyed fabric against laccases is required during simultaneous applications e.g. in detergent formulations or washing steps after dyeing.

PEG modification of proteins can lead to stabilisation in aqueous media with increased halflives, higher solubility and stability in organic solvents manufacture (Inada et al. 1995). However little is reported about laccase modification in scientific papers. Due to the chain flexibility and extensive hydration of PEG (Kinstler et al. 2002) proteins modified with this polymer occupy larger volumes in an aqueous environment, which should affect their adsorption behaviour and their enzymatic activity towards macromolecular substrates.

In this study, a laccase from $T$. hirsuta was modified by attachment to monomethoxy PEG in order to restrict enzyme action to solubilzed dye molecules. The characteristics (oxidation of fibre bound dye, kinetics, stability etc.) of the modified and the native enzyme are compared.

\section{Materials and methods}

\section{Chemicals and enzyme}

Monomethoxy polyethylene glycol (M.W. 5,000, 2,000 , and 1,100) was supplied by Fluka (Buchs, Switzerland) while cyanuric chloride, 2,2-azinobis(3-etylbenzothiazoline-6-disulfonic acid (ABTS), 2,6-dimethoxyphenol, 2-methoxyphenol, chatechol, Indigo Carmine and Remazol Briliant Blue R (RBBR) were from Sigma. Further the Coomassie Brilliant Blue reagent was purchased by BioRad (Hercules, USA). All other chemicals and solvents were of analytical grade. Cultivation of Trametes hirsuta (IMA2002) and purification of the laccase is described elsewhere (Almansa et al. 2004).

Synthesis of the laccase PEG-conjugates

In brief, $0.8 \mathrm{mmol}$ of methoxypolyethylene glycol were dissolved in $100 \mathrm{ml}$ of dried toluene and activated with $2.4 \mathrm{mmol}$ cyanuric chloride in the presence of $60 \mathrm{mmol}$ sodium carbonate at $40^{\circ} \mathrm{C}$ for $40 \mathrm{~h}$. Activated polymer was precipitated in $300 \mathrm{ml}$ of petroleum ether. $2 \mathrm{ml}$ of the T. hirsuta laccase solution $\left(1 \mathrm{mg} \mathrm{ml}^{-1}\right.$ protein) were mixed in $100 \mathrm{ml}$ sodium borate buffer (0.1 M; pH 9.3) containing $3.0 \mathrm{~g}$ of 2-O-methoxypolyethylene glycol-4,6-dichloro-s-triazine. The reaction mixture was shaken for $2 \mathrm{~h}$ at room temperature. Unbound polymer was removed partially by ultra filtration, using a Vivaflow 50 (M.W.cutoff 30000) (Vivascience, Hanover, Germany) prior to the chromatographic purification described below. Different conjugates were prepared with PEG 1,100, PEG 2,000, and PEG 5,000, using the same molar ratio.

Hydrophobic interaction chromatography (HIC)

Preliminary studies on different HIC media and buffers were performed using an Äkta chromatography system and a HIC selection kit (Amersham Pharmacia, Uppsala, Sweden) containing a Phenyl Sepharose High Performance, a Phenyl Sepharose 6 Fast Flow (low sub), a Phenyl Sepharose 6 Fast Flow (high sub), Butyl Sepharose 4 Fast Flow, and an Octyl Sepharose 4 Fast Flow media. As binding buffer a phosphate buffer (50 mM, pH 7.0) containing $\left(\mathrm{NH}_{4}\right)_{2} \mathrm{SO}_{4}$ at different concentrations $(0.6,1.0,2.0$, and $3.0 \mathrm{M})$ was used. The gradient volume with a linear flow rate of $1 \mathrm{ml} \mathrm{min}^{-1}$ was 15 column volumes to elute with the final buffer, a phosphate buffer (50 mM, pH 7.0), detection at $280 \mathrm{~nm}$ and $610 \mathrm{~nm}$. Prior to analysis the corresponding amount of salt in the binding buffer was added to the sample (sample volume $500 \mu \mathrm{l}$ ) and mixed thoroughly.

Collected fractions were analysed measuring laccase activity using ABTS as described below and determining the molecular mass profile using gel filtration with a Superdex 75 HR 10/30 column (Amersham Pharmacia), sample volume $200 \mu \mathrm{l}$, detection at $280 \mathrm{~nm}$, using a phosphate buffer (0.1 M, pH 7.0) containing sodium chloride

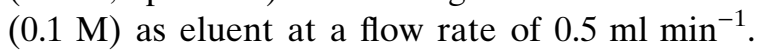
Determination of molecular weight was calculated according a protein calibration kit obtained 
from Sigma. For efficient purification of large amounts of PEG modified laccase an Octyl Sepharose media in a XK50/20 column was used.

\section{Laccase activity and stability}

Protein concentration and laccase activity on ABTS (2,2'-azino-bis(3ethylbenzthiazolline-6-sulfonic acid; $\epsilon_{436}=29300 \mathrm{M}^{-1} \mathrm{~cm}^{-1}$ ) and were measured as previously described (Almansa et al. 2004). For the kinetic calculation different concentrations ranging from 2 to $100 \mu \mathrm{M}$ ABTS in succinate buffer $(25 \mathrm{mM}, \mathrm{pH} 4.5)$ were measured.

In order to determine the effects of PEG coupling on the thermal stability, the residual activity against ABTS of the different conjugates was assayed after different incubation times at $50^{\circ} \mathrm{C}$. The $\mathrm{pH}$ stability and optima were determined similarly using citrate phosphate buffer $(50 \mathrm{mM})$ with $\mathrm{pH}$ values from 3.0 to 6.5 .

\section{Decolourisation of commercial dyes}

Indigo Carmine (C.I. 74) and RBBR (C.I. 19) $(0.1 \mathrm{mM})$ were dissolved in citrate phosphate buffer $100 \mathrm{mM}$ at various $\mathrm{pH}$ levels between 3.0 and 6.0. Optimum conditions for dye decolorization were elaborated using an experimental design with two factors ( $\mathrm{pH}$, temperature) at four different levels, varying from 3.0 to $6.0(\mathrm{pH})$, from 30 to $60^{\circ} \mathrm{C}$ (temperature), based on a full factorial design set up with the Design Expert 6.0 software program (StateEase Inc., USA). $1 \mathrm{ml}$ of enzyme solution was added to $10 \mathrm{ml}$ of dye solution $(0.1 \mathrm{mM})$, gently mixed and incubated at the appropriate temperature. After the desired incubation time the reaction was stopped by inhibition of laccase activity with $200 \mu \mathrm{l}$ of a $1 \mathrm{M} \mathrm{NaF}$ solution. Dye solutions incubated with inhibited enzyme were used as reference.

\section{Cotton staining}

Dyeing of cotton fabrics was performed in three steps at $40^{\circ} \mathrm{C}$ in alkaline conditions (ratio 1:20). First, the fabrics were immersed in a dyeing solution with $2 \%$ o.w.f of the dye (Reactive Blue 19) and $50 \mathrm{~g} \mathrm{l}^{-1}$ of sodium chloride in an AHIBA Spectradye dyeing apparatus (Datacolor) machine. After $15 \mathrm{~min}, 5 \mathrm{~g} \mathrm{l}^{-1}$ of sodium carbonate were added to the solution followed by the addition of $1 \mathrm{ml}$ of sodium hydroxide after $30 \mathrm{~min}$. The samples were left for $75 \mathrm{~min}$ at $40^{\circ} \mathrm{C}$ and then removed from the machine to wash with water at $70^{\circ} \mathrm{C}$ for $10 \mathrm{~min}$ and with a $0.25 \mathrm{~g} \mathrm{l}^{-1}$ solution of the non-ionic detergent Hostapal (clariant) at boiling temperature for $15 \mathrm{~min}$ to remove the unfixed dye, and allowed to air dry.

Dye removal from fabric

RBBR stained cotton fabrics and commercial jeans denim $(3 \times 3 \mathrm{~cm})$ were incubated by gentle shaking fabrics in $10 \mathrm{ml}$ of citrate phosphate buffer (100 mM, pH 4.0 and 6.0) containing $0.3 \mathrm{U} \mathrm{ml}^{-1}$ of different laccase conjugates at $50^{\circ} \mathrm{C}$ for four hours. Thereafter the reaction was stopped by adding $1 \mathrm{ml}$ of a $1 \mathrm{M} \mathrm{NaF}$ solution and the fabrics were rinsed with distilled water and air dried. The colour of the dyed fabrics was evaluated using a reflectance measuring Datacolor apparatus (ACS II Spectrometer) at standard illuminant D65 (LAV/Spec. Incl., d/8, D65/10 ${ }^{\circ}$. Five areas on each sample were measured in various positions, and the results represent average values. $\Delta E$ values represent the colour difference compared to untreated fabrics.

\section{Enzyme adsorption experiments}

Adsorption isotherms were calculated by gently shaking fabrics $(3 \times 3 \mathrm{~cm})$ in $10 \mathrm{ml}$ of enzyme solutions at $4{ }^{\circ} \mathrm{C}$ for two hours. Prior to the measurements the fabrics were pre-treated by boiling the fabric in a solution of sodium hydroxide $0.5 \mathrm{M}$ containing a non ionic detergent $1 \mathrm{~g} \mathrm{l}^{-1}$ for $120 \mathrm{~min}$ with a ratio $1: 15$. After the pre-treatment the fabrics were well washed under tab water, rinsed three times with demineralized water, air dried overnight at room temperature and cut into pieces of $3 \times 3 \mathrm{~cm}$. The fabrics were pre-tempered for one hour at $4^{\circ} \mathrm{C}$ before adding the enzyme with concentrations of $7 \mathrm{mg} \mathrm{l}^{-1}$. The decrease in enzyme protein concentration was followed according to Bradford, using Coomassie Brilliant Blue (protein assay Biorad). Determinations were carried out in duplicates with bovine serum albumin as standard. The data were correlated by the 
Freundlich adsorption isotherm expressed as $Q /$ $M=K_{\mathrm{f}} \cdot C_{\mathrm{enz}}^{(1 / n)}$, where $Q$ is the amount of enzyme adsorbed, $M$ the weight of adsorbent, $C_{\mathrm{enz}}$ is the enzyme concentration, and $K_{\mathrm{f}}$ as well as $1 / n$ are the Freundlich parameters. The parameters for the Freundlich equation were determined by least-squares regression from the linear plots of $\log (Q / M)$ vs. $\log C_{\text {enz }}$ (Kandelbauer et al. 2004).

\section{Results}

Synthesis and purification of the PEG conjugates

In gel filtration chromatography, laccase activity of the modified conjugates shifted towards shorter retention times compared to the native $T$. hirsuta laccase. This confirms an increased molecular weight due to attachment of the PEG. Furthermore, the absence of native enzyme in the gel filtration pattern indicated a quantitative coupling of the enzyme to the activated PEG polymer.

Efficient separation of PEG conjugates, PEG and native laccase was achieved with Phenyl Sepharose 6 FF (low sub) and Octyl Sepharose 4 FF for all the different conjugates (Fig. 1). Thereby the retention time of the modified laccase was longer compared to the native enzyme and increased with increased amount of salt in the binding buffer and decreased chain length of attached PEG. Fractions with laccase activity against ABTS were further analysed by gel filtration and complete removal of unbound activated polymer and native enzyme was confirmed (Fig. 1).

Characterisation of the laccase conjugates

According to gel filtration the molecular weight of the laccase was increased to different extends by covalent attachment of PEG with varying chain lengths (Table 1). Interestingly, after PEG modification, the stability of the laccase conjugates increased with the molecular weight of the PEG chain attached onto the enzyme but had no effect on the $\mathrm{pH}$ optima and stability (data not shown). Further kinetic parameters of the native laccase and its different conjugates using ABTS as substrate confirmed a certain impact of the polymer chain length attached onto the enzyme. The substrate affinity for the laccase conjugate decreased with increasing molecular weight of attached PEG (Table 1).

Treatment of cotton and denim fabrics

Using an experimental design with two factors at four different levels optimum degradation of Indigo Carmine was found to be at $\mathrm{pH} 6.0$ and $50^{\circ} \mathrm{C}$ and at $\mathrm{pH} 4.0$ and $40^{\circ} \mathrm{C}$ for Remazol Brilliant Blue R (RBBR). The suggested models fit well for obtained values and the Model $F$-values of 11.01 and 10.36 imply that the models are significant. Since the degradation at $50^{\circ} \mathrm{C}$ did not differ from the optimum conditions further experiments were
Fig. 1 Gel filtration patterns from different solutions using a Superdex 75 HR 10/30 column are shown: Native laccase from $T$. hirsuta (a), reaction mixture after modification (b) and purified conjugate (5 kDA PEG) (c)

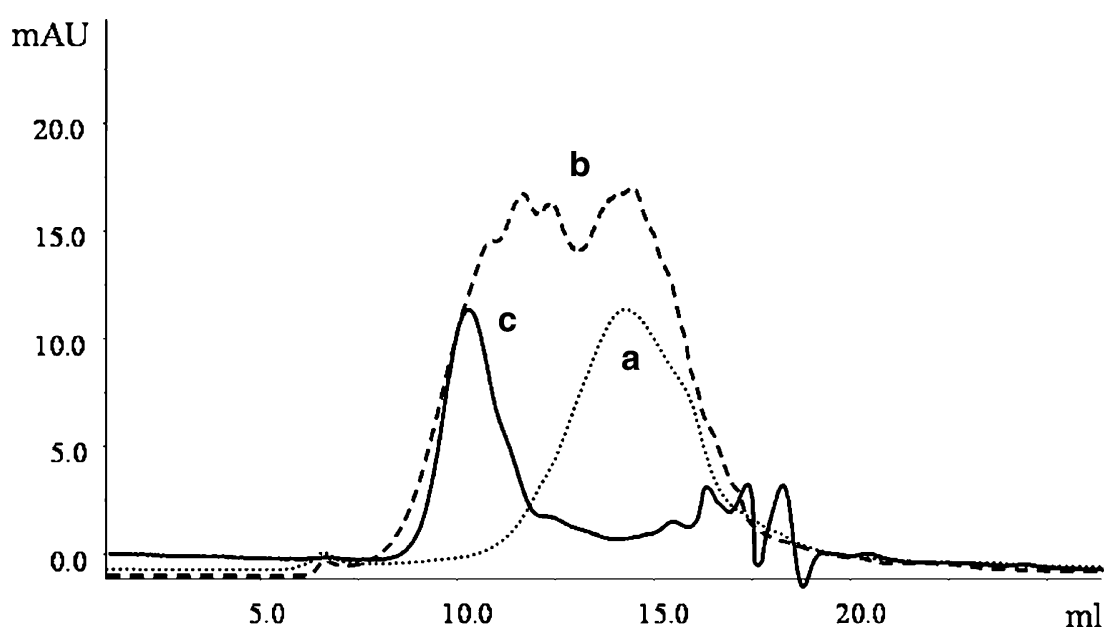


Table 1 Molecular weight, thermo stability, kinetic parameters, and calculated Freundlich parameter $\left(K_{\mathrm{f}}\right)$ for protein adsorption on cotton of the different laccase PEG conjugates on ABTS

\begin{tabular}{lclll}
\hline & $\begin{array}{l}\text { native } \\
\text { enzyme }\end{array}$ & $\begin{array}{l}\text { Conjugate with } \\
1.1 \mathrm{kDa} P E G\end{array}$ & $\begin{array}{l}\text { Conjugate with } \\
2 \mathrm{kDa} \text { PEG }\end{array}$ & $\begin{array}{l}\text { Conjugate with } \\
5 \mathrm{kDa} \text { PEG }\end{array}$ \\
\hline $\mathrm{M} . \mathrm{W} .[\mathrm{kDa}]$ & $52 \pm 4$ & $85 \pm 6$ & $177 \pm 6$ & $269 \pm 7$ \\
$\mathrm{Half}$ life at $50^{\circ} \mathrm{C}[\mathrm{min}]$ & $140 \pm 20$ & $70 \pm 20$ & $150 \pm 20$ & $210 \pm 20$ \\
$\mathrm{Km}[\mu \mathrm{M}]$ & $1.34 \pm 0.02$ & $5.00 \pm 0.04$ & $6.32 \pm 0.05$ & $7.04 \pm 0.08$ \\
$V_{\max }\left[\mu \mathrm{M} \mathrm{s}^{-1}\right]$ & $2.36 \pm 0.03$ & $3.83 \pm 0.05$ & $6.03 \pm 0.09$ & $4.73 \pm 0.07$ \\
$K_{\mathrm{f}}$ & $3.49 \times 10^{-4}$ & $9.68 \times 10^{-5}$ & $2.77 \times 10^{-5}$ & $1.17 \times 10^{-4}$ \\
\hline
\end{tabular}

performed at $50^{\circ} \mathrm{C}$ for both dyes. Degradation of RBBR in solution was monitored at different incubation times for modified and native laccase from T. hirsuta (data not shown).

The fabrics were incubated with native and modified laccase at the same level of activity against ABTS. Treatment of the dyed fabric with native enzyme resulted in higher differences of the $\mathrm{K} / \mathrm{S}$ values compared to the control than with the laccase PEG conjugate. The K/S value shifted from 47.96 to 46.35 for the native enzyme while covalent attachment of PEG onto the enzyme resulted in protection of dyed fibres against decolorization; 47.96 to 47.60 for the $5 \mathrm{kDa}$ PEG laccase conjugate (Fig. 2). Additionally only the samples treated with the native laccase showed a higher $\Delta \mathrm{E}$ compared to the conjugates. The extent of modification only played a minor role. The results obtained for the enzymatic treatment of jeans confirmed the values obtained with cotton treatment (data not shown).

Adsorption of the native laccase from T. hirsuta onto cotton was higher than for the different

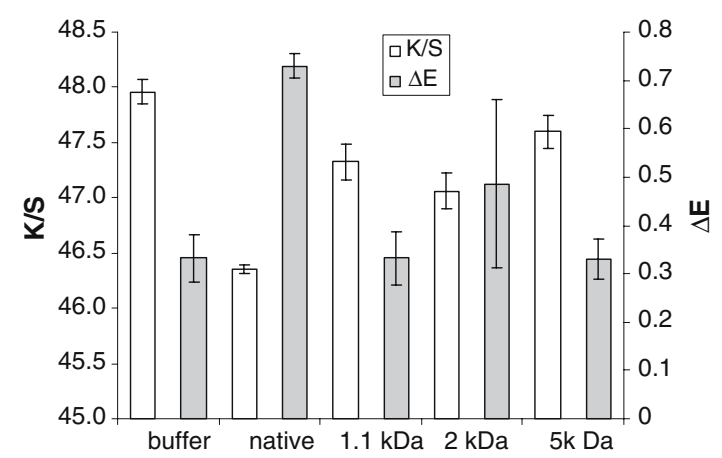

Fig. 2 Biotreatment of cotton fabrics dyed with Remazol Brilliant Blue $\mathrm{R}$ in citrate phosphate buffer $(25 \mathrm{mM} \mathrm{pH}$ 4.0) at $50^{\circ} \mathrm{C}$ with native laccase from $T$. hirsuta, 1.1, 2.0, and $5.0 \mathrm{kDa}$ PEG conjugates. K/S (white bars) and $\Delta E$ (grey bars) values measured after four hours of incubation time
PEG conjugates (Table 1). However, no clear tendency could be identified within the different conjugates in relation to the attached size of polymer on the various carrier materials.

\section{Discussion}

A strategy for coupling of PEG to proteases using 2,4,6 trichloro-s-triazine activation was developed replacing one chlorine atom by the polymer chain. The two remaining chlorine atoms on the triazine should allow the activated polymer to react preferably with the $\epsilon$-amino group of lysine residues on the surface of the proteins (Inada et al. 1995). Since hydroxide is a laccase inhibitor (Xu 1997) the reaction mixture was concentrated in order to prepurify and to change $\mathrm{pH}$.

Hydrophobic interaction chromatrography (HIC) was found to be a fast alternative to the time consuming gel filtration for effective separation of the laccase conjugate from unbound polymer. In the case of PEG conjugates the polymer moiety can interact with the protein surface groups, the hydrophobic ligands on the HIC gel, and the role of salt modulating these interactions (Vincentelli et al. 1999). Basically the hydrophobic character of the matrix should disfavour PEG binding, which is the case for unbound polymer. The different interaction behaviour of the 1.1 and $5 \mathrm{kDa}$ conjugates can be explained by the argument mentioned above. Actually, based on this principle a PEG-dextran biphasic system was exploited to determine the modification extent (Delgado et al. 1997). However, this is not the case for the native enzyme showing less interaction compared to the conjugates. This inverse relationship may lie in the surface modification due to covalent attachment of the polymer. Chromatographic elution patterns 
should be cautiously interpreted (Vincentelli et al. 1999).

Due to both the high flexibility of its backbone chain and the bound water molecules, the hydrodynamic volumes of PEG and the protein are very different. Therefore, the PEG molecule shows an apparent higher molecular weight when compared with a protein. However, using proteins for calibration to assess the molecular weight from the different retention times mean numeric values for the size of PEG modified laccases were obtained by gel filtration confirming increased molecular weights. Interestingly, after PEG modification, the stability of the laccase conjugates increased slightly only for 2 and $5 \mathrm{kDa}$ conjugates with the molecular weight of the PEG chain attached onto the enzyme. On the opposite, modification with the smallest PEG led to decreased stability. Previously, the enhanced stability of PEG-trypsin was explained with the formation of a highly hydrogen-bonded structure around the enzyme preventing proteolytic auto degradation (Gaertner and Puigserver 1992). Kinetic parameters of the native laccase and its different conjugates indicate that sterical hindrance by the polymer chains might restrict the substrate affinity for the conjugates. Similar results were reported previously for modified protease from $B$. lentus and macromolecular substrates where steric hindrance will become a major factor in the larger conjugates (Schroeder et al. 2004).

A method was established to measure dye degradation with native and modified laccase. Sodium fluoride which is a strong inhibitor for laccases binding on the type $2 \mathrm{Cu}^{2+}$ of the laccaseactive site (Naqui and Varfolomeev 1980) was used to stop the laccase reaction. Best conditions for enzymatic degradation of Remazol Brilliant Blue R (RBBR) were found to be at $\mathrm{pH} 4.0$ and $40^{\circ} \mathrm{C}$. These values correlated well with the moderate temperature and the $\mathrm{pH}$ between 3 and 4 mentioned for fungal laccases in the literature (Deveci et al. 2004).

For some laccases biodegradation of RBBR was only observed in the presence of small molecular weight redox mediators (Sorares et al. 2001). However, the laccase from T. hirsuta was also able to degrade synthetic dyes without any mediator. Although 1-hydroxybenzotriazol led to higher activity, biodegradation was performed in this study without mediator in order to determine the effect of attached polymer (Rodriguez Couto et al. 2005).

Compared to conjugates, the native laccase was capable of degrading the fabric bound remazol. Similarly, degradation of other fabric-bound dyes like Indigo by laccase has been reported (Campos et al. 2001). In general, PEG modification can restrict the access of the enzyme to substrates due to sterical hindrance or limitation of diffusion into fibrous materials. For this particular application in destaining of dyes solubilized from fabrics, PEG modification should limit adsorption of the enzymes into fibres and garments preventing their enzymatic decolorization. The increase of hydrophobicity due to the attachment of polyethylene glycol benefits the usage of proteins in some applications (Sookhumnerd and Hsu 2000). Here we have demonstrated that enzyme adsorption onto fabrics was decreased due to PEG-modification most likely due to the hydrophobic character of the resulting conjugates. However, protein adsorption can also be affected by other factors like e.g. $\mathrm{pH}$, salt concentration (Yin et al. 2000) or the charge of the protein (enzyme) surface (Longo and Combes 1997). Former studies have shown an impact of chain length of PEG attached on the enzymatic activity of proteases (Schroeder et al. 2005). These observations could be confirmed in this study with laccases for kinetic parameters in solution. However, the chain length of the different conjugates did not significantly influence the laccase activity on fibres.

Concluding the results of this study we clearly showed that chemical modification of the laccase from $T$. hirsuta can reduce decolourisation of fabrics while retaining activity of dye solubilized during washing processes. Thus, chemical modification of the laccase has high potential for prevention of colour re-deposition during household laundry cleaning.

Acknowledgements The authors wish to thank the European Union for the financial funding of the PROTEX Project from 5th framework program. 


\section{References}

Abadulla E, Silva LM, Cavaco P, Guebitz GM (2000) Enzymatic decolorization of textile dyeing effluents. Text Res J 70:409-414

Almansa E, Kandelbauer A, Pereira L, Cavaco P, Guebitz GM (2004) Influence of structure on dyedegradation with laccase mediator systems. Biocatal Biotransform 22:315-324

Andreaus J, Campos R (2001) Reduction of indigo backstaining by post washing. Melliand Int 7:318-320

Campos R, Kandelbauer A, Robra KH, Cavaco-Paulo A, Guebitz GM (2001) Indigo degradation with purified laccases from Trametes hirsuta and Sclerotium rolfsii. J Biotechnol 89:131-139

Cavaco-Paulo A (1998) Mechanism of cellulase action in textile processes. Carbohydr.Polym 272:273-277

Delgado C, Malmsten M, Van Alstine JM (1997) Analytical partioning of poly(ethylene glycol)-modified proteins. J Chromatogr B 692:263-272

Gaertner HF, Puigserver AJ (1992) Increased activity and stability of poly(ethylene glycol)-modified trypsin. Enzyme Microb Technol 14:150-155

Galante YM, Formantici C (2003) Enzyme applications in detergency and in manufacturing industries. Curr Org Chem 7:1399-1422

Inada Y, Furukawa M, Sasaki H, Kodera Y, Hiroto M, Nishimura H, Matsushima A (1995) Biomedical and biotechnological applications of PEG- and PM-modified proteins. Trends Biotechnol 13:86-91

Kandelbauer A, Maute O, Kessler RW, ErlacherA, Gübitz GM (2004) Study of dye decolorization in an immobilized laccase enzyme-reactor using online spectroscopy. Biotechnol Bioeng 87:552-563

Kinstler O, Molineux G, Treuheit M, Laad D, Gegg C (2002) Mono-N-terminal poly(ethylene glycol)-protein conjugates. Adv Drug Deliv Rev 54:477-485

Longo MA, Combes D (1997) Influence of surface hydrophilic/hydrophobic balance on enzyme properties. J.Biotechnol 58:21-32
Naqui A, Varfolomeev SD (1980) Inhibition mechanism of Polyporus laccase by fluoride ion. FEBS Letters 113:157-160

Nyanhongo GS, Gomes J, Guebitz GM, Zvauya R, Read JSA (2002) Decolorization of textile dyes by laccases from a newly isolated strain of Trametes modesta. Water Res 36:1449-1456

Rodriguez Couto S, Sanromán M, Guebitz GM (2005) Influence of redox mediators and metal ions on synthetic acid dye decholorization by crude laccase from Trametes hirsuta. Chemosphere 58:417-422

Schroeder M, Schweitzer M, Lenting HBM, Guebitz GM (2004) Chemical Modification of Proteases for Wool Cuticle Scale Removal. Biocatal Biotransfor 22:299_ 305

Schroeder M, Lenting HBM, Kandelbauer A, Silva CSJM, Cavaco-Paulo A, Guebitz GM (2005) Restricting detergent protease acon to surface of protein fibres by chemical modification. Appl Microbol Biotechnol in press

Sookhumnerd T, Hsu JT (2000) Purification of PEG-protein conjugates by countercurrent distribution in aqueous two-phase systems. J Liq Chrom Re Technol 23:497-503

Sorares GMB, Pessoa de Amorim MT, Costa-Ferreiras M (2001) Use of laccase together with redox mediators to decolourize Remazol Brilliant Blue R. J Biotechnol 89:123-129

Vincentelli J, Paul C, Azarkan M, Guermant C, El Moussaoui A, Looze Y (1999) Evaluation of the polyethylene glycol-KF-water system in the context of purifying PEG-protein adducts. Int J Pharm 176:241-249

Xu F (1997) Effects of redox potential and hydroxide inhibition on the $\mathrm{pH}$ activity profile of fungal laccase. J Biol Chem 272:924-928

Yin G, Janson JC, Liu Z (2000) Characterization of protein adsorption on membrane surface by enzyme linked immunoassay. J Membrane Sci 178:99-105 